\title{
R-HD-MTX/ARA-C Regimen
}

National Cancer Institute

\section{Source}

National Cancer Institute. R-HD-MTX/ARA-C Regimen. NCI Thesaurus. Code C140103.

A reg imen consisting of rituximab, high-dose (HD) methotrexate (MTX) and HD

cytarabine (AraC) that can be used in the treatment of central nervous system (CNS)

lymphoma and refractory or relapsed (RR) non-Hodgkin lymphoma (NHL). 